\title{
A Wireless Ear Canal's Temperature Monitoring System for an Intensive Care Patient
}

\author{
Darunee Chaythong ${ }^{*}$, and Saner Sa-ad
}

\begin{abstract}
This paper presents the design of a wireless ear canal's temperature monitoring system for an intensive care patient aiming to keep track of the body temperature change in each period of time. Since temperature is routinely measured, body temperature is one of the few health measurements that could be applied for disease surveillance. The system has the potential to detect and warn doctor and nurse can be recognized and characterized temperature early. It was designed to measure the temperature from the auditory canal by infrared sensors and automated temperature recording and deployed by a computer via Bluetooth. A microcontroller was used to control the system. The result of testing was found that capably measure the temperature in the range of values $27-47^{\circ} \mathrm{C}$. The margin of temperature measurement error was less than $\pm 0.5^{\circ} \mathrm{C}$. The operating distance was not less than 12 meters.
\end{abstract}

Keywords-Temperature measurement, ear canal, intensive care patient, Bluetooth, microcontroller

\section{INTRODUCTION}

$\mathrm{I}_{\mathrm{n}}^{\mathrm{N}}$ $\mathrm{N}$ the medical measurement of body temperature is necessary and significant to diagnose patient's condition surveillance. As the temperature changes will affect a protein structure in the human body and involve the digestive enzymes are followed changes. The typical body temperature is $37^{\circ} \mathrm{C}$ approximately, but if it is higher than $45^{\circ} \mathrm{C}$ that will be lead to destroy a structure of enzymes and risk to be harmful health condition. Conversely, if it is lower than $34^{\circ} \mathrm{C}$ that will be fallen in metabolism (Metabolic) of the body which may affect cardiac malfunction so crisis (Arrhythmia) atrial fibrillation. It is necessary to have a body temperature monitoring for an intensive care patient to collect data and warn doctors or nurses when an unusual body temperature condition occurred [1]-[2].

There are many methods to measure the body temperature. For example, the measurement of the level of the core body organ temperature (deep body temperature), such as the heat, lungs or abdominal organs commonly used a thermometer measures in the rectum [1]. It's easily and accurate temperature when it's measured from a middle ear or esophagus [2]. Therefore, it was proposed to analyze the inner ear disease by analysis of the reflected sound wave to convert

*Darunee Chaythong is with the Electronic Engineering Department, Rajamangala University of Technology Srivijaya, Boryang, Songkhla, Thailand, 90000

Saner Sa-ad is an assistant professor. He is now with the Electronic Engineering Department, Rajamangala University of Technology Srivijaya, Boryang, Songkhla, Thailand, 90000. in temperature and the chemicals in the inner ear [3]. The measurement is begin with generating a signal and sent it through the ear canal, after that waiting the reflected signal to the microphone to analyze the characteristic response of liquid inside the ear. The temperature was evaluated from the radiated infrared's reflected ray from a middle ear or an eardrum. The core body temperature is shown on the liquid crystal which was installed in this equipment. In addition, the ear's temperature monitoring was reported while the temperature value was processing [4]. Because it necessary to monitor the level of core body temperature all time so a tidy heater was needed to compensate heat that was lost by the external environment and as it was shown via the liquid crystal display.

From all above it was found that there was not a data management system to record, display, monitor and warn the body temperature change of intensive care patient system immediately and automatically that be beneficial for physician or nurse to keep track of the patient. The monitoring system was designed by measuring the temperature with analyze the infrared radiation that spread out from middle ear or the eardrum which is an important aware temperature point of the core organs body precisely and transfer these data via a wireless communication (Bluetooth) to process by a computer. The system was designed to have capability automated collecting data and automated signal alert when it in a risk point. It will be a facility element for doctors and nurses can be informed of the patient problem early. As a result, the patient treatment will be in the timely manner.

\section{PROCEDURE OF DESIGN}

\section{A. The temperature measurement and data transmission}

The system was designed to continuous measure the inner ear temperature by an infrared sensor for a 8-hour's period and sent signal data through Bluetooth while recording all into the memory and display. The components of system separated into 2 parts; the set of temperature and wireless transmission, and the set of the record information, and display, as shown in Fig 1.

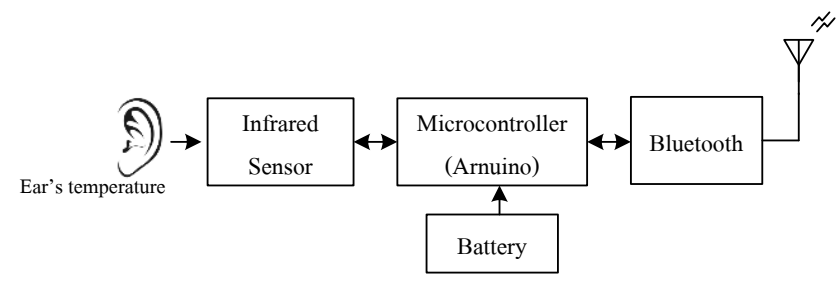

(a) The temperature measurement and data transmission 
\&

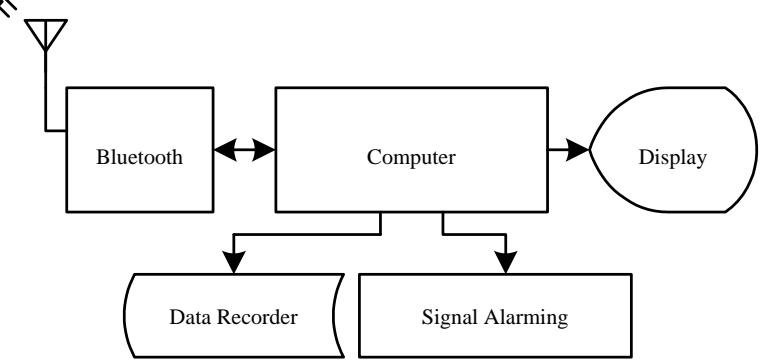

(b) Data Recorder and Display

Fig. 1 The wireless ear canal's temperature monitoring system for an intensive care patient

(a) The temperature measurement and data transmission

(b) Data Recorder and Display

From Fig 1. (a) The temperature measurement set and the wireless transmission are presented consist of microcontroller (Arduino) that controlled system performance by sending the signals to control the infrared sensor function by detect the temperature and transfer to a data recorder via Bluetooth and display. The measurement of an ear plug is a part of measurement set. It was designed to measure the body temperature through the ear canal. It was flexibility and proper for measuring in an ear canal. An infrared sensor was composed inside it, as shown in the Fig 2.

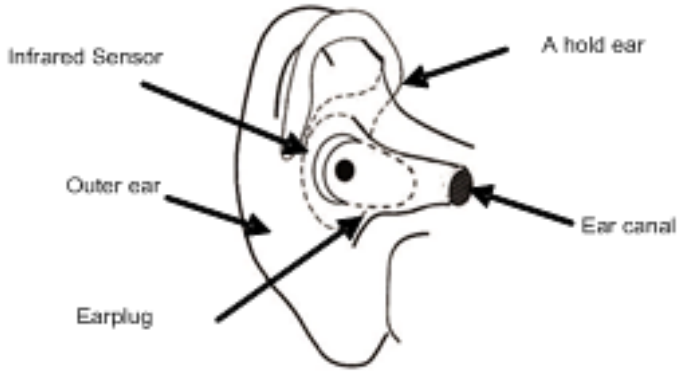

Fig. 2 The ear plug in a patient's ear canal

The design of temperature measurement inside the ear canal focuses on monitoring of the temperature change and easily usage; therefore, it was powered by a battery size 9 volt in a circuit, and probability to collecting the temperature data in a computer's memory in the data logger maximum format every 5 seconds. The communication between microcontrollers and infrared sensors through a serial port U-art format same as the microcontrollers and Bluetooth as well. The Control circuit system inside the ear plug via a microcontroller and wireless displays, as shown in Fig. 3.

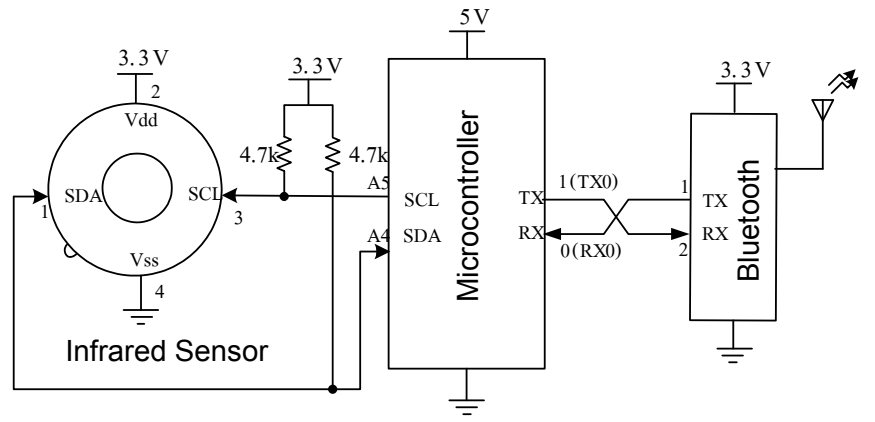

Fig. 3 A circuit of a wireless ear canal's temperature monitoring system for an intensive care patient with microcontroller

\section{B. Data Recorder and Display}

The data recorder that used to record the temperature data from the measurement set in previous and a controlled display are controlled by microcontroller via Bluetooth. The processing program is a Delphi. It received the data from the temperature sensor set and records in a data logger format and displays the temperature status both in the numbers and graphs form. And it is ready to alert when the body temperature is lower than $34^{\circ} \mathrm{C}$ or higher than $39^{\circ} \mathrm{C}$ [1],[5] , the flowchart of the data recorder and display shown in Fig. 4.

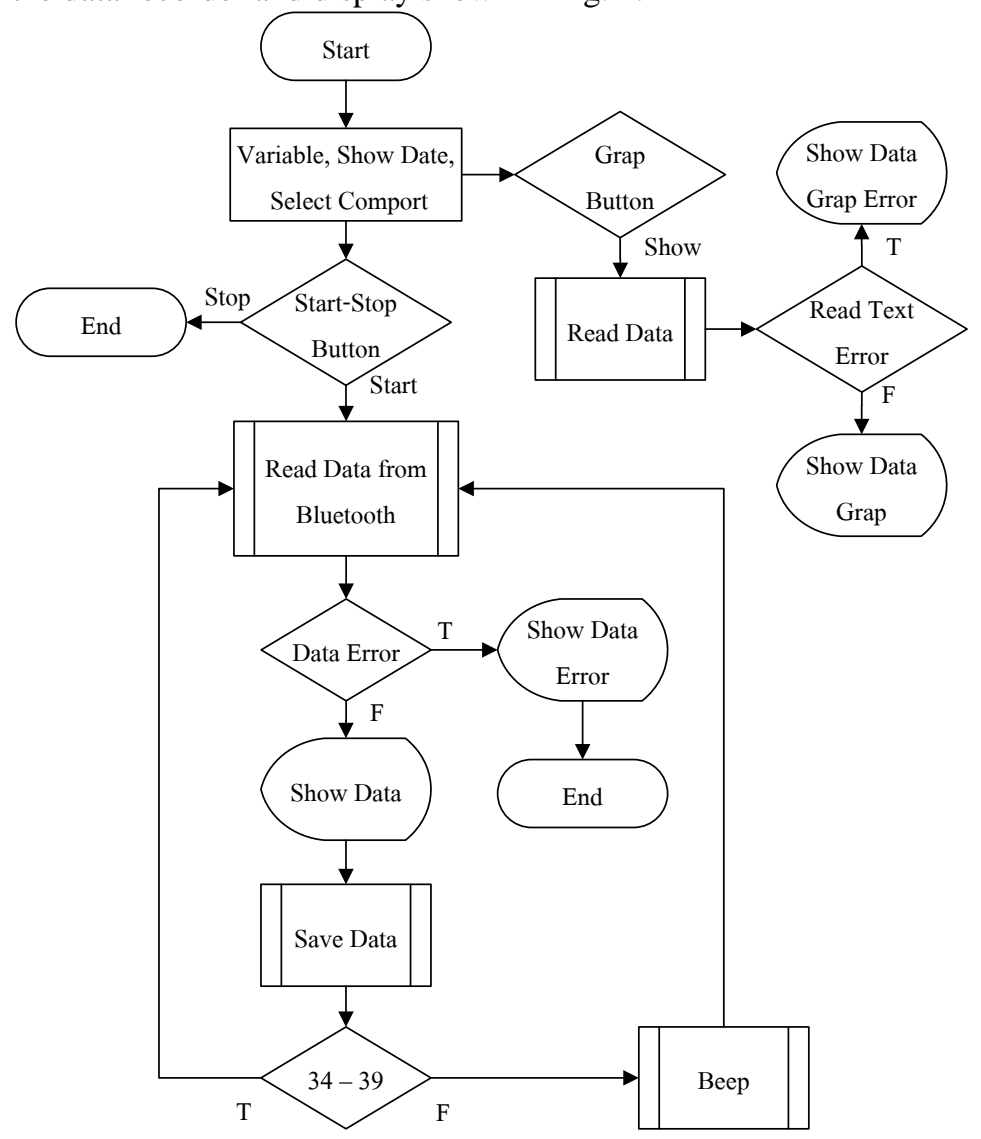

Fig. 4 Flowchart of the record and display program of the wireless ear canal's temperature monitoring system for an intensive care patient

From Fig. 4, when the processing program starts, it pops up a user's window to select a communication port between the computer and Bluetooth. After that it starts receiving the temperature data from the measurement set and show it on thewindow while checking and comparing these data with the set point. If it has changed equal interval data gain, the system will be warning. It records and displays every 5 seconds. The data recording format includes day, month, year, time and temperature. It can check the previous data all time, as shown in Fig. 5. 


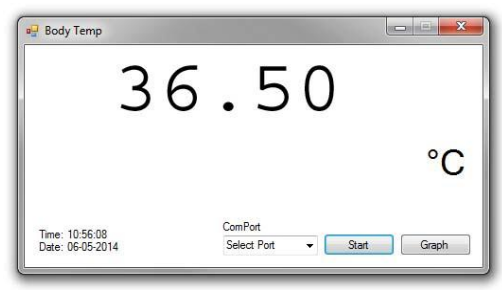

(a) a numeric form

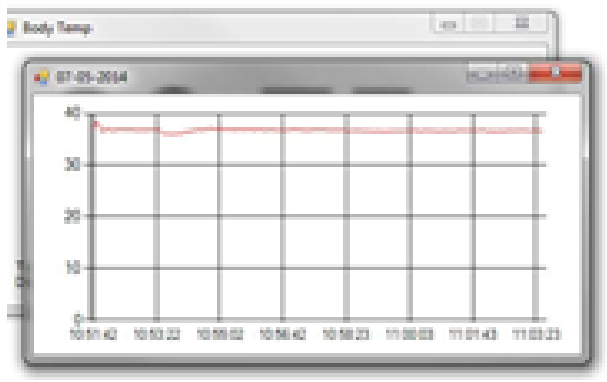

(b) a graph form

Fig. 5 A temperature display forms on the Window

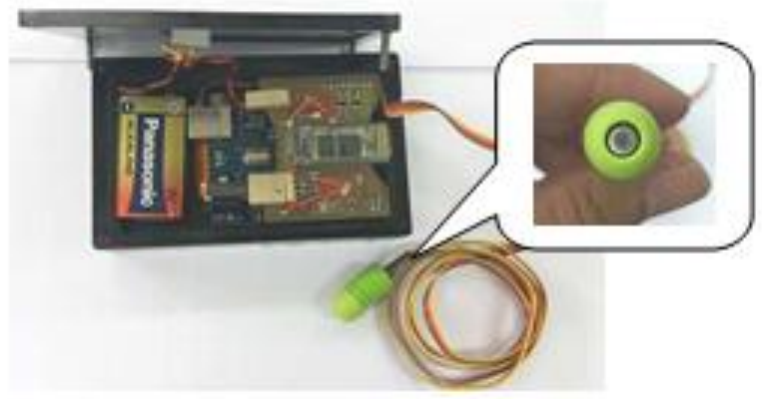

Fig. 6 The prototype of the wireless ear canal's temperature monitoring system of an intensive care patient

\section{THE EXPEREMENT RESULT}

The wireless ear's canal temperature monitoring system for an intensive care patient presents as shown in Fig. 6. It was tested the measure performance. Firstly, it was testing of the infrared sensors accuracy. As shown in Fig. 7, a heat source for an unreflecting light plate and the temperature while infrared thermometer using, and then compared distances of between a sensor and a heating plate. The spacing was 0.5 centimeter, 1 centimeter, 1.5 centimeter and 2 centimeter, respectively. This experiment for 3 replications.

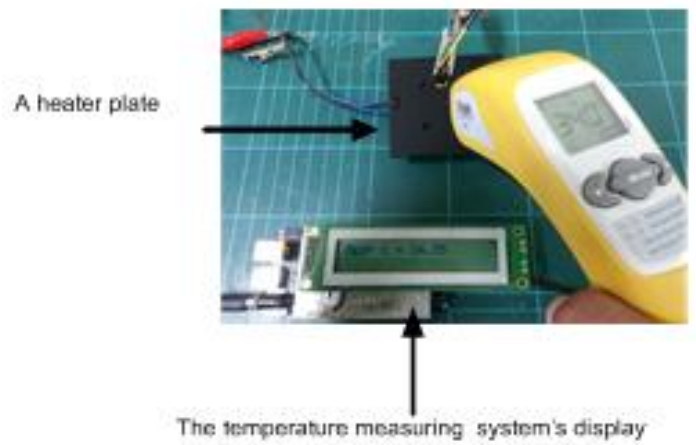

Fig. 7 The operated testing between an infrared sensor device and an infrared thermometer

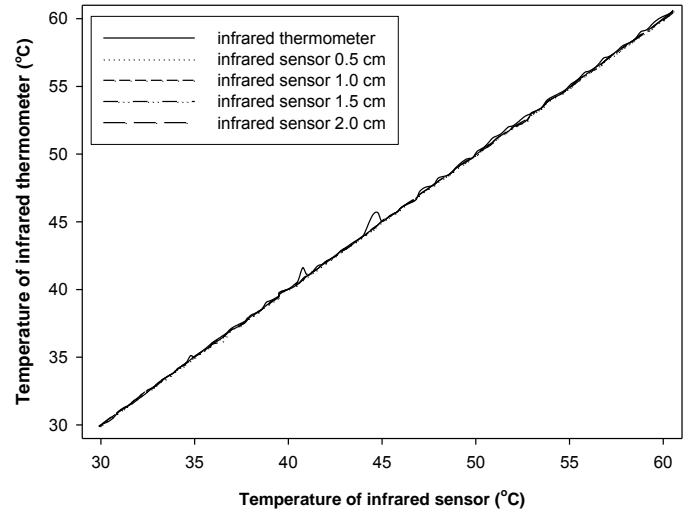

Fig. 8 the results of temperatures testing between an infrared sensor device and an infrared thermometer

Fig. 8 shows the measured temperature testing compare between a wireless monitoring system and an infrared thermometer during a distance range of values 0.5-2 centimeter in the temperature range of values $30-60^{\circ} \mathrm{C}$. The result shows the different maximum value of two methods is $0.3^{\circ} \mathrm{C}$ or 0.75 percent.

Fig. 9 shows the result of the measured temperate in auditory canal comparing between the tracking system and an infrared thermometer with a volunteer. The result of the system shows the data are similar with errors not more than $0.5^{\circ} \mathrm{C}$ as shown in Table 1

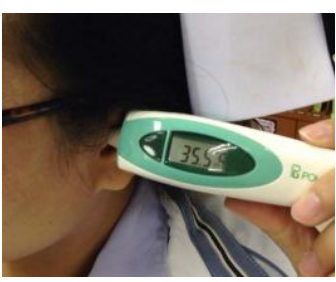

(a)

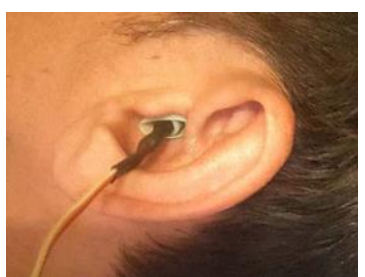

(b)
Fig. 9 Comparison between the temperature's measurements testing on the volunteer's ear (a) an infrared thermometer (b) a tracking system

TABLE I

COMPARING EAR'S TEMPERATURE TESTING

\begin{tabular}{ccc}
\hline \hline $\begin{array}{c}\text { Volunteers } \\
\text { number }\end{array}$ & $\begin{array}{c}\text { A wireless monitoring } \\
\text { system's temperature } \\
\left({ }^{\circ} \mathrm{C}\right)\end{array}$ & $\begin{array}{c}\text { An infrared thermometer } \\
\text { 'temperature } \\
\left({ }^{\circ} \mathrm{C}\right)\end{array}$ \\
\hline 1 & 36.45 & 36.50 \\
2 & 36.85 & 37.20 \\
3 & 36.75 & 36.80 \\
4 & 35.55 & 35.50 \\
5 & 35.50 & 35.00 \\
6 & 37.00 & 37.00 \\
7 & 36.80 & 37.00 \\
8 & 36.50 & 36.40 \\
9 & 37.50 & 37.60 \\
10 & 38.00 & 37.70 \\
\hline \hline
\end{tabular}

From Table I shows the comparing of the measured ear's temperature testing between two systems when they were experimented on 10 volunteers. The result shows the error of two systems not more than $0.5^{\circ} \mathrm{C}$ 


\section{CONCLUSION}

The wireless ear canal's temperature monitoring system for an intensive care patient was presented has a potential to both automated detecting and deploying of the body temperature data in real-time. However this system was limited to measure in only one patient. In the future this application can be extended to monitor " $\mathrm{N}$ " number of patients and improving a smaller ear plug which has the most effective battery power.

\section{REFERENCES}

[1] Sorachai Srisuma, "Energy Metabolism and Thermoregulatory Physiology," Lesson sheet of the department of physiology. Faculty of medicine, Mahidol University.pp 1-37,[online]: http://www.ps.si.mahidol.ac.th/courseware/StoreResources/51_PaO_En ergyMetBodytemp.pdf

[2] Wanachat Krataijun, "Temperature" [online]: http://student.mahidol.ac.th/ u4809160/body_temp.htm

[3] J. Geoffrey, K. Sandra and K. David, "Apparatus and Method for Analysis of Ear Pathologies Using Combination of Acoustic Reflectance, Temperature and Chemical Response", the patent number U.S 5951486A, Sep. 14, 1999.

[4] F. Jacob and K.F. Richard, "Ear Temperature Monitor and Method of Temperature Measurement", the patent number U.S 6773405B2, Aug. 10, 2004.

[5] Sangsom Siripanich, "the protection and care for low temperature (Hypothemia) during cold weather", Report on Epidemiological Surveillance Weekly year 43 issue 2: 20, 2012.

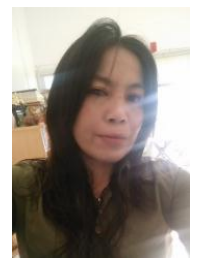

Darunee Chaythong was born in Songkhla, Thailand. She received the B.S.Ed.(Second class honors) in Telecommunications Engineering from the King Mongkut's Institute of Ladkrabang (KMITL), angkok, Thailand, in 1994 and the M.S.Tech.Ed. in Electrical Technology from the King Mongkut's Institute of Bangkok (KMITNB), Bangkok, Thailand in 2002.

Since 1994 she has been a lecturer at the electronic department, faculty of engineering, Rajamangala University of Technology Srivijaya (RMUTSV), Boryang, Songkhla, Thailand, Her research interests are mainly in electronic circuits design and application.

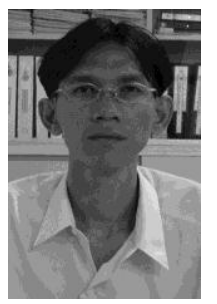

Saner Sa-ad was born in Songkhla, Thailand. He received the B.Eng. and M.Eng in Electronic Engineering from the King Mongkut's Institute of Technology Ladkrabang (KMITL), Bangkok, Thailand, in 1999 and 2005.

Since 1999 he has been a lecturer at the electronic department, faculty of engineering, Rajamangala University of Technology Srivijaya (RMUTSV), Boryang, Songkhla, Thailand, where he is currently an Assistant Professor in Department of Electronic Engineering. His research interests are mainly in electronic circuits design and application. 